\title{
Salicylate-induced hearing loss and gap detection deficits in rats
}

\section{Kelly E. Radziwon ${ }^{1}{ }^{*}$, Daniel J. Stolzberg ${ }^{1,2}$, Maxwell E. Urban ${ }^{1}$, Rachael A. Bowler ${ }^{1}$ and Richard J. Salvi ${ }^{1}$}

1 Department of Communicative Disorders and Sciences, Center for Hearing and Deafness, University at Buffalo, The State University of New York, Buffalo, NY, USA

${ }^{2}$ Department of Physiology and Pharmacology, Schulich School of Medicine and Dentistry, University of Western Ontario, London, ON, Canada

\section{Edited by:}

Arnaud Norena, Université de

Provence, France

Reviewed by:

Larry Roberts, McMaster University, Canada

Mark Nelson Wallace, Medical

Research Council, UK

*Correspondence:

Kelly E. Radziwon, Department of

Communicative Disorders and

Sciences, Center for Hearing and

Deafness, University at Buffalo, The

State University of New York, 137

Cary Hall, 3435 Main Street, Buffalo,

NY 14214, USA

e-mail: radziwon@buffalo.edu
To test the "tinnitus gap-filling" hypothesis in an animal psychoacoustic paradigm, rats were tested using a go/no-go operant gap detection task in which silent intervals of various durations were embedded within a continuous noise. Gap detection thresholds were measured before and after treatment with a dose of sodium salicylate $(200 \mathrm{mg} / \mathrm{kg})$ that reliably induces tinnitus in rats. Noise-burst detection thresholds were also measured to document the amount of hearing loss and aid in interpreting the gap detection results. As in the previous human psychophysical experiments, salicylate had little or no effect on gap thresholds measured in broadband noise presented at high-stimulus levels (30-60 dB $\mathrm{SPL})$; gap detection thresholds were always $10 \mathrm{~ms}$ or less. Salicylate also did not affect gap thresholds presented in narrowband noise at $60 \mathrm{~dB}$ SPL. Therefore, rats treated with a dose of salicylate that reliably induces tinnitus have no difficulty detecting silent gaps as long as the noise in which they are embedded is clearly audible.

Keywords: gap detection, operant conditioning, threshold, tinnitus, prepulse inhibition, rat model, sodium salicylate, sensorineural hearing loss

\section{INTRODUCTION}

The ototoxic effects of high doses of salicylate, the active ingredient in aspirin, are well-established (1-4). A recent review by Sheppard et al. (5) details the peripheral and central effects of salicylate along with the known perceptual deficits seen in humans following large doses of aspirin (5). Peripherally, acute doses of salicylate affect outer hair cell $(\mathrm{OHC})$ and auditory nerve function, causing a reduction in distortion product otoacoustic emissions (DPOAE) and cochlear compound action potentials (CAP), respectively $(6,7)$. Centrally, systemic administration of salicylate amplifies sound-evoked activity in the auditory cortex (AC) to high-intensity sounds despite reduced neural output from the cochlea $(8,9)$. Also, salicylate alters spontaneous firing rates $(10)$ and tonotopic organization in the AC (7).

In addition to electrophysiological studies, some of the perceptual effects of salicylate have been cataloged. Depending upon the dose, humans and rats typically develop hearing loss, with temporary threshold shifts of $\sim 5-20 \mathrm{~dB}$ SPL, following salicylate administration $(1,2,11,12)$. In addition to hearing loss, salicylate also disrupts auditory temporal processing for normal-hearing human listeners. With moderate doses of aspirin, McFadden et al. (13) found increased gap detection thresholds (impaired temporal resolution) at low sound-pressure levels and flatter than normal temporal integration functions (impaired temporal integration). These aspirin-induced changes in temporal resolution and temporal integration are similar to the temporal processing deficits seen in listeners with sensorineural hearing loss $(14,15)$. Thus, aspirininduced hearing loss has been proposed as a model of temporary sensorineural hearing loss in humans (13).

In addition to inducing temporary hearing loss and temporal processing deficits, salicylate also reliably induces tinnitus, i.e., a phantom auditory perception, in humans (2). Given its tinnitusinducing properties, salicylate was used to test the first animal model of tinnitus (16), and most of the current animal behavioral models of tinnitus have been assessed using salicylate [see Ref. $(17,18)$ for recent reviews of animal models of tinnitus]. Regarding behavioral models of tinnitus, one of the most widely used animal behavioral paradigm for tinnitus uses a modified gap detection paradigm. Based on the hypothesis that tinnitus fills in the silent gap, the gap prepulse inhibition of the acoustic startle reflex (Gap-PPI) paradigm has been used to assess both salicylate- and noise-induced tinnitus in a number of species (19-25).

In a typical Gap-PPI paradigm, a $50 \mathrm{~ms}$ silent interval embedded in $60 \mathrm{~dB}$ SPL continuous noise is presented $\sim 100 \mathrm{~ms}$ before a high-intensity noise burst used to evoke the startle reflex motor response $(26,27)$. Normal subjects hear the silent gap, which functions as a warning signal (cue) that the startle stimulus is about to occur, and reduces the amplitude of the startle reflex. However, the "tinnitus gap-filling" hypothesis postulates that if a subject has tinnitus, the phantom sound "fills in silence" and interferes with processing of the silent gap, thereby preventing the silent interval from inhibiting the startle reflex. The greatest deficit in Gap-PPI presumably occurs when the spectral properties of the background noise match the tinnitus pitch (28-30). Consequently, narrowband noise (NBN) Gap-PPI has been used to estimate the tinnitus pitch $(19,29,31)$.

Gap-PPI has been widely used by many researchers, including our group, to identify animals that presumably have noise- or drug-induced tinnitus (19-21, 23). Gap-PPI paradigms attempt to avoid the problem of drug- or noise-induced impairments in temporal resolution by employing $50 \mathrm{~ms}$ gaps presented in 
at least $60 \mathrm{~dB}$ SPL background noise, durations and intensities that are typically well above threshold. Therefore, researchers have assumed that impaired Gap-PPI is not due to impaired temporal resolution per se, but rather to tinnitus interfering with the processing of the silent gap (24).

However, since the effect of salicylate on auditory temporal resolution has not been directly investigated in rats, it is not clear whether temporal processing deficits, hearing loss, tinnitus, or some other perceptual deficit can explain changes in Gap-PPI performance following salicylate administration $(1,32)$. Therefore, the goal of the current study is to determine the effects of salicylate on conscious gap detection performance in rats.

To evaluate basic temporal resolution in rats, we treated rats with a dose of salicylate $(200 \mathrm{mg} / \mathrm{kg}$ IP) known to induce tinnitus (4) and obtained gap detection thresholds for broadband and NBNs. If the $50 \mathrm{~ms}$ gaps in $60 \mathrm{~dB}$ background noise cannot be detected after salicylate treatment, then this would support the hypothesis that tinnitus fills in silent intervals in their conscious perceptions. However, if gap detection thresholds remain largely unchanged following salicylate administration, then it is unlikely that tinnitus is filling in the silent interval and preventing the $50 \mathrm{~ms}$ gap from being consciously perceived. Although the conscious perception of silent gaps in psychoacoustic tasks is likely different than the mechanisms involved in the subcortical Gap-PPI paradigm, this study will provide important information for evaluating what is modeled in animal models of tinnitus, i.e., hearing loss, temporal processing deficits, or hyperacusis (32).

\section{MATERIALS AND METHODS SUBJECTS}

Six female Sprague-Dawley rats were used in the gap detection experiments, and three of these six rats were used to obtain noise thresholds (Note: two rats developed tumors and had to be sacrificed before their gap detection thresholds in NBN could be obtained, and one rat had a broken tooth preventing her from being used during the NBN detection experiment). The rats began training at $\sim 4$ months of age and they were tested until they were 14-15 months of age. The rats were obtained from Charles River Laboratories and all procedures were approved by the University at Buffalo, SUNY's Institutional Animal Care and Use Committee. All rats were housed separately and were kept on a $12 \mathrm{~h}$ day/night cycle (lights on at 6 a.m.; lights off at 6 p.m.). Rats were food restricted and kept at $\sim 85 \%$ of their free-feeding weight during the course of the experiment. Test sessions lasted $\sim 1 \mathrm{~h}$, and the rats were run once per day, 6-7 days/week.

\section{GAP DETECTION PROCEDURES \\ Apparatus}

Rats were tested in an acoustically transparent acrylic cage $(28 \mathrm{~cm} \times 30 \mathrm{~cm} \times 38 \mathrm{~cm})$ located inside a sound attenuating chamber $(76 \mathrm{~cm} \times 71 \mathrm{~cm} \times 71 \mathrm{~cm})$ lined with $5 \mathrm{~cm}$ thick sound attenuating foam (Illbruck, Inc., Minneapolis, MN, USA). The behavior of the animals during test sessions was monitored by a digital camera (Fire-i Digital Camera, Unibrain, San Ramon, CA, USA). The test cage was equipped with a speaker (FT28D Dome Tweeter, Fostex, Tokyo, Japan), feeder (Med Associates Model
ENV-203M, St. Albans, VT, USA), and nose-poke hole equipped with infrared sensors (Vulintus, Dallas, TX, USA).

The experiment was run using custom behavioral software running on a personal computer (Microsoft Windows XP) similar to that described previously (4). The custom software controlled Tucker-Davis Technologies (TDT, Gainesville, FL, USA) system-3 equipment and operant hardware. Sound stimuli were generated with TDT hardware and software (TDT RX6 processor, D/A converter, $\sim 100 \mathrm{kHz}$ sampling rate); digital inputs to and outputs from the testing cages were controlled by the TDT RX6 processor interfaced to a pellet feeder (Med Associates Model SG-501, St. Albans, VT, USA) and infrared sensors (Vulintus, Dallas, TX, USA). TDT RPvds software and custom MATLAB software (MathWorks, Nattick, MA, USA) were used to control all aspects of the experiment. Sound-pressure levels were calibrated using a sound level meter (Larson-Davis System 824) equipped with a microphone (1/4" free field microphone, model 2520, Larson-Davis, Depew, NY, USA) placed at the position where the animal's head would be when it poked its nose into the nose-poke hole.

\section{Procedure}

The stimuli used in the gap detection experiments were a continuous broadband noise (BBN) containing frequencies up to $42 \mathrm{kHz}$, and 3 continuous NBNs: $10-20 \mathrm{kHz}$ ( 1 octave bandwidth, centered at $14.14 \mathrm{kHz}), 16-20 \mathrm{kHz}$ ( $4 \mathrm{kHz}$ bandwidth), and $15.3-16.7 \mathrm{kHz}$ (1/8th octave bandwidth centered at $16 \mathrm{kHz}$ ). The BBN was presented at 20,30, 40, and $60 \mathrm{~dB} \mathrm{SPL}$, and the NBNs were presented at $60 \mathrm{~dB}$ SPL. The rats were trained using a go/no-go operant conditioning procedure to detect a silent gap embedded within the continuous noise.

The rat began a trial by nose poking through the nose-poke hole, which initiated a variable waiting interval ranging from 1 to $4 \mathrm{~s}$. During this time, the rat had to maintain its position in the nose-poke hole; failure to do so resulted in an aborted trial. After the waiting interval, a single silent gap was presented in the noise. In the go condition, the target stimulus was the silent gap. In this trial type, a hit was recorded if the rat correctly responded to the gap within $2 \mathrm{~s}$ by removing its nose from the nose-poke hole and receiving a food pellet $(45 \mathrm{mg}$ dustless rodent grain pellets, BioServ, Frenchtown, NJ, USA). A miss was recorded if the rat failed to remove its nose from the nose-poke.

Approximately $30 \%$ of all trials were catch trials. These constituted the no-go part of the procedure and the silent gap was absent during these trials. False alarm (FA) rates and response biases were calculated from these catch trials. If the rat removed its nose during a catch trial, a false alarm was recorded and the rat received a $4 \mathrm{~s}$ timeout, during which the house light was turned off and the rat could not initiate another trial. However, if the subject continued to nose-poke, a correct rejection was recorded. No reinforcement was given for a correct rejection, but the next trial began immediately. Chance performance was represented by the animal's false alarm rate. Sessions were excluded from analysis if the percentage of FAs was $>20 \%$. Less than $1 \%$ of all sessions were excluded for this reason.

The target stimuli were presented according to the psychophysical method of constant stimuli (MOCS). Within each 10-trial block, 7 predetermined targets were presented randomly along 
with 3 catch trials. During testing, the target gaps were chosen so that the smallest one or two gaps were rarely detected by the rats, whereas the largest gaps were well above threshold and nearly always detected. The gap durations used for testing were adjusted depending on each rat's performance.

\section{Sodium salicylate administration}

After baseline gap detection thresholds were collected, the rats were tested once per week with either a single injection of sodium salicylate $(200 \mathrm{mg} / \mathrm{kg} \mathrm{IP})$ dissolved in saline $(50 \mathrm{mg} / \mathrm{ml})$, or an equivalent volume of saline (control). The injections were administered $2 \mathrm{~h}$ before testing. The $200 \mathrm{mg} / \mathrm{kg}$ dose of sodium salicylate has previously been shown to reliably induce tinnitus-like behavior in rats $(4,33)$.

\section{Data analysis}

Signal detection analysis was employed to factor out the animals' motivational biases (34). Mean hit and false alarm rates were used to calculate all gap thresholds using signal detection theory and a threshold criterion of $d^{\prime}=1.5$. This $d^{\prime}$ value is comparable to that used by others (35-37) and ensures that the animal is responding primarily to the target stimuli and not randomly (38).

\section{NOISE DETECTION PROCEDURES}

\section{Apparatus}

The apparatus for this part of the study was the same as that used in the gap detection experiment.

\section{Procedure}

The spectra of the noise-burst stimuli used in the noise detection experiments were the same as in the gap detection study, namely, BBN and the three NBNs $(10-20,16-20$, and $15.3-16.7 \mathrm{kHz})$. Each noise stimulus was $300 \mathrm{~ms}$ in duration with cosine rise/fall times of $5 \mathrm{~ms}$. Rats were trained using a go/no-go operant conditioning procedure to detect a noise burst in an otherwise quiet chamber.

The procedure for obtaining the noise-burst thresholds was nearly identical to the procedures used in the gap detection experiment, but the target stimuli in the go condition for this experiment were noise bursts embedded in a quiet background. Approximately $30 \%$ of all trials were catch trials, and no stimulus was presented on no-go trials. Noise-burst threshold testing began when the animals finished the gap detection experiment. As in the gap detection experiment, noise bursts were presented using the MOCS. The target intensities were chosen so that only the lowest one or two intensities were not detected whereas the highest sound levels were well above threshold.

\section{Sodium salicylate administration}

After baseline noise-burst thresholds were collected, the rats were tested once per week with either a single injection of sodium salicylate $(200 \mathrm{mg} / \mathrm{kg} \mathrm{IP})$ dissolved in saline $(50 \mathrm{mg} / \mathrm{ml})$ or an equivalent volume of saline (control). As in the gap detection experiments, the injections were administered $2 \mathrm{~h}$ before testing.

\section{Data analysis}

The data analysis for this study was the same as that used in the gap detection experiment.

\section{RESULTS}

\section{GAP DETECTION}

\section{Gap detection in broadband noise}

Table 1 shows the individual and mean gap detection thresholds in BBN at 30, 40, and $60 \mathrm{~dB}$ SPL for baseline, saline, and salicylate conditions along with gap detection thresholds for $20 \mathrm{~dB}$ SPL for baseline and saline conditions. Data could not be collected for the $20 \mathrm{~dB}$ SPL-salicylate condition because the rats were unable to perform the task. This was most likely due to the salicylate-induced hearing loss that resulted in the $20 \mathrm{~dB} B B N$ being below or near the threshold of audibility as determined in the subsequent threshold detection experiment (Table 1).

\section{Effect of intensity on BBN gap thresholds}

Figure 1A shows the mean BBN gap thresholds at 30, 40, and $60 \mathrm{~dB}$ SPL for all six rats for baseline, saline, and salicylate conditions. In addition, the gap thresholds for baseline and saline are shown for $20 \mathrm{~dB}$ SPL; however, we were unable to collect reliable data for salicylate at $20 \mathrm{~dB}$ SPL. For baseline and saline conditions, mean BBN gap detection thresholds increased slightly from $\sim 2$ to $3 \mathrm{~ms}$ as the sound level decreased from 60 to $30 \mathrm{~dB}$ SPL, but at $20 \mathrm{~dB}$ SPL, gap thresholds increased to 4-6 ms. A two-way repeated measures analysis of variance (ANOVA) of the baseline and saline gap threshold obtained at 20-60 dB SPL showed a significant effect of intensity $(F=15.77,3 \mathrm{df} ; p<0.001)$ and a significant interaction between intensity and baseline and saline conditions $(F=11.79$,

Table 1 | Individual and mean broadband noise gap thresholds (ms) vs. intensity (dB SPL) for baseline, saline, and salicylate conditions.

\begin{tabular}{|c|c|c|c|c|c|}
\hline Subject & Condition & $\begin{array}{c}\text { BBN } \\
\text { (60 dB SPL) }\end{array}$ & $\begin{array}{c}\text { BBN } \\
\text { (40 dB SPL) }\end{array}$ & $\begin{array}{c}\text { BBN } \\
\text { (30 dB SPL) }\end{array}$ & $\begin{array}{c}\text { BBN } \\
\text { (20 dB SPL) }\end{array}$ \\
\hline \multirow[t]{3}{*}{ Green 1} & Baseline & $2.1 \mathrm{~ms}$ & $2.1 \mathrm{~ms}$ & $2.7 \mathrm{~ms}$ & $3.7 \mathrm{~ms}$ \\
\hline & Saline & $1.8 \mathrm{~ms}$ & $2.3 \mathrm{~ms}$ & $2.2 \mathrm{~ms}$ & $3.8 \mathrm{~ms}$ \\
\hline & Salicylate & $2.0 \mathrm{~ms}$ & $2.9 \mathrm{~ms}$ & $11.3 \mathrm{~ms}$ & $\mathrm{NC}$ \\
\hline \multirow[t]{3}{*}{ Green 2} & Baseline & $1.3 \mathrm{~ms}$ & $1.6 \mathrm{~ms}$ & $2.4 \mathrm{~ms}$ & $2.9 \mathrm{~ms}$ \\
\hline & Saline & $1.7 \mathrm{~ms}$ & $1.8 \mathrm{~ms}$ & $2.7 \mathrm{~ms}$ & $5.7 \mathrm{~ms}$ \\
\hline & Salicylate & $1.5 \mathrm{~ms}$ & $2.6 \mathrm{~ms}$ & $3.9 \mathrm{~ms}$ & $\mathrm{NC}$ \\
\hline \multirow[t]{3}{*}{ Green 3} & Baseline & $1.8 \mathrm{~ms}$ & $1.7 \mathrm{~ms}$ & $2.7 \mathrm{~ms}$ & $3.9 \mathrm{~ms}$ \\
\hline & Saline & $1.9 \mathrm{~ms}$ & $2.0 \mathrm{~ms}$ & $1.7 \mathrm{~ms}$ & $6.9 \mathrm{~ms}$ \\
\hline & Salicylate & NA & $3.8 \mathrm{~ms}$ & NA & $\mathrm{NC}$ \\
\hline \multirow[t]{3}{*}{ Purple 1} & Baseline & $1.9 \mathrm{~ms}$ & $2.1 \mathrm{~ms}$ & $2.7 \mathrm{~ms}$ & $3.3 \mathrm{~ms}$ \\
\hline & Saline & $2.3 \mathrm{~ms}$ & $2.0 \mathrm{~ms}$ & $2.4 \mathrm{~ms}$ & $3.7 \mathrm{~ms}$ \\
\hline & Salicylate & $2.2 \mathrm{~ms}$ & $2.5 \mathrm{~ms}$ & $5.2 \mathrm{~ms}$ & $\mathrm{NC}$ \\
\hline \multirow[t]{3}{*}{ Purple 2} & Baseline & $1.5 \mathrm{~ms}$ & $2.4 \mathrm{~ms}$ & $3.0 \mathrm{~ms}$ & $7.9 \mathrm{~ms}$ \\
\hline & Saline & $1.7 \mathrm{~ms}$ & $2.6 \mathrm{~ms}$ & $2.8 \mathrm{~ms}$ & $9.7 \mathrm{~ms}$ \\
\hline & Salicylate & $1.6 \mathrm{~ms}$ & $4.5 \mathrm{~ms}$ & $17.7 \mathrm{~ms}$ & $\mathrm{NC}$ \\
\hline \multirow[t]{3}{*}{ Purple 3} & Baseline & $1.8 \mathrm{~ms}$ & $1.8 \mathrm{~ms}$ & $2.9 \mathrm{~ms}$ & $4.4 \mathrm{~ms}$ \\
\hline & Saline & $2.2 \mathrm{~ms}$ & $1.5 \mathrm{~ms}$ & $2.5 \mathrm{~ms}$ & $6.5 \mathrm{~ms}$ \\
\hline & Salicylate & $1.4 \mathrm{~ms}$ & $3.0 \mathrm{~ms}$ & $12.0 \mathrm{~ms}$ & $\mathrm{NC}$ \\
\hline \multirow[t]{3}{*}{ Mean } & Baseline & $1.72 \mathrm{~ms}$ & $1.94 \mathrm{~ms}$ & $2.71 \mathrm{~ms}$ & $4.32 \mathrm{~ms}$ \\
\hline & Saline & $1.93 \mathrm{~ms}$ & $2.03 \mathrm{~ms}$ & $2.38 \mathrm{~ms}$ & $6.05 \mathrm{~ms}$ \\
\hline & Salicylate & $1.74 \mathrm{~ms}$ & $3.22 \mathrm{~ms}$ & $10.02 \mathrm{~ms}$ & $\mathrm{NC}$ \\
\hline
\end{tabular}

NA, data not available; NC, data not collected. 
$3 \mathrm{df}, p<0.001)$. A Holm-Sidak multiple comparison of the baseline condition revealed a significant difference in gap thresholds between 20 and $60 \mathrm{~dB}$ and 20 and $40 \mathrm{~dB}(p<0.01)$; a similar analysis of the saline condition revealed a significant difference between 20 and $30 \mathrm{~dB}, 20$ and $40 \mathrm{~dB}$, and 20 and $60 \mathrm{~dB}(p<0.05)$.

Mean gap thresholds during salicylate treatment were similar to baseline and saline at $60 \mathrm{~dB}$ SPL (Figure 1A; Table 1). At $40 \mathrm{~dB}$ SPL, mean gap thresholds increased from $2 \mathrm{~ms}$ pre-treatment to about $3 \mathrm{~ms}$ during salicylate; however, at $30 \mathrm{~dB}$ SPL, gap detection thresholds increased from $\sim 3 \mathrm{~ms}$ pre-treatment to roughly $10 \mathrm{~ms}$ during salicylate, but did not exceed $18 \mathrm{~ms}$ in any of the salicylate-treated rats (Table 1; range: $3.9-17.7 \mathrm{~ms}$ ).

A two-way repeated measures ANOVA with three sound levels (30, 40, and $60 \mathrm{~dB}$ SPL) and three conditions (baseline, saline, and salicylate) as factors revealed a significant effect of condition $(F=14.77,2 \mathrm{df}, p<0.001)$, intensity $(F=16.50,2 \mathrm{df}$, $p<0.001)$, and a significant interaction between condition and sound level $(F=9.53,4 \mathrm{df}, p<0.001)$. A Holm-Sidak post hoc analysis revealed significant differences between the salicylate and saline conditions $(p<0.05)$ at $30 \mathrm{~dB}$ SPL and between salicylate and baseline conditions $(p<0.05)$ at $30 \mathrm{~dB}$ SPL, but not at 40 and $60 \mathrm{~dB}$ SPL $(p>0.05)$. Within the saline treatment group, the Holm-Sidak post hoc analysis revealed a significant difference between 30 and $60 \mathrm{~dB}$ SPL $(p<0.05)$ and 30 and $40 \mathrm{~dB}$ SPL $(p<0.05)$. No significant differences were found between the baseline and saline conditions for any of the sound levels $(p>0.05)$.

Mean BBN gap detection thresholds for the saline and salicylate conditions were subsequently re-plotted by sensation level ( $\mathrm{dB}$ $\mathrm{SL}$ ) in Figure 1B to more clearly illustrate the effects of salicylateinduced hearing loss on gap detection performance. The mean SLs were calculated by subtracting the mean thresholds from the noiseburst detection experiment (dB SPL) from the sound presentation level of the stimulus. In addition, gap detection thresholds were also plotted for normal-hearing Mongolian gerbils across five sensation levels (35). The reason for including the gerbil data was to demonstrate that gap detection deficits are apparent with decreasing sound level in normal-hearing animals with similar hearing sensitivity and temporal processing abilities as rats. Therefore, when corrected for hearing loss and re-plotted by sensation level, the gap detection deficits seen following an injection of salicylate appear to be the result of hearing loss alone without the additional explanation of tinnitus "filling in" the silent gap.

\section{Gap detection in narrowband noise}

Gap detection thresholds were also obtained at $60 \mathrm{~dB}$ SPL for three NBNs (10-20, 16-20, and 15-17 kHz) located near the most sensitive region of the rat's audiogram and in the vicinity of the presumed tinnitus pitch $(7,19,39)$. The purpose of this experiment was to determine if salicylate-induced tinnitus could "fill-in" the silent gap in NBN. Table 2 shows the gap detection thresholds in BBN and the three NBNs at $60 \mathrm{~dB}$ SPL for each rat across the baseline, saline, and salicylate conditions. Mean thresholds for the four rats are plotted in Figure 2 (two of the six rats previously tested in the BBN condition died before their gap detection thresholds in NBN could be obtained), and mean psychometric functions are plotted in Figure 3. Generally, gap detection thresholds increased as the bandwidth of the noise became narrower; however, gap detection thresholds for each NBN did not change significantly after the rats were injected with salicylate.

In a two-way repeated measures ANOVA with three conditions (baseline, saline, and salicylate) and four noise bandwidths (BBN, 10-20, 16-20, and $15-17 \mathrm{kHz}$ ) as factors, the gap threshold differences among the three conditions were not great enough to exclude the possibility that the differences were due to chance $[F(2,45)=0.42, p>0.05]$, and there was no significant interaction between condition and bandwidth $[F(6,45)=2.16, p>0.05]$.

\section{NOISE THRESHOLDS}

Table 3 shows broadband and NBN thresholds in quiet for each of the three rats that were tested in the baseline, saline, and salicylate conditions (Note: two of the original six rats died before noise
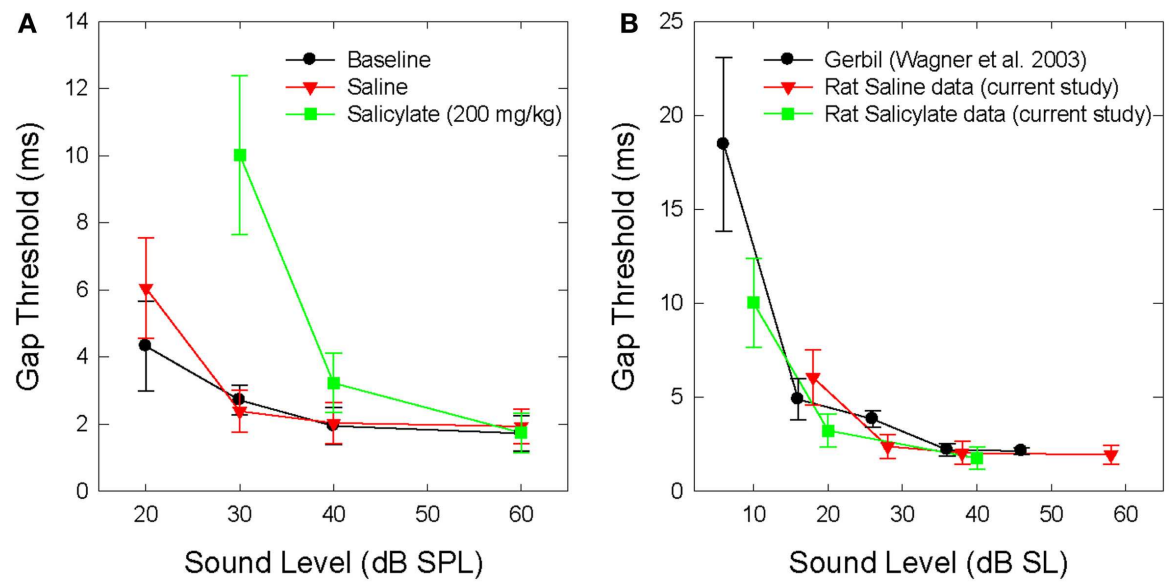

FIGURE 1 | (A) Mean (SEM) gap thresholds for BBN presented at intensities from 20 to $60 \mathrm{~dB}$ SPL for baseline, saline, and salicylate (SS, $200 \mathrm{mg} / \mathrm{kg}$ ) conditions. Gap thresholds could not be measured at $20 \mathrm{~dB}$ SPL during salicylate treatment. (B) Mean (SEM) gap detection

thresholds for the current saline and salicylate (SS, $200 \mathrm{mg} / \mathrm{kg}$ ) data re-plotted in dB SL (sensation level). Mean (SEM) gap detection thresholds for white noise are also plotted for the Mongolian gerbil across five sensation levels (35). 
Table 2 | Individual and mean gap detection thresholds (ms) for broadband noise (BBN) and narrowband noise (NBN) at $60 \mathrm{~dB}$ SPL.

\begin{tabular}{|c|c|c|c|c|c|}
\hline Subject & Condition & $\begin{array}{l}\text { BBN } \\
\text { (60 dB } \\
\text { SPL) }\end{array}$ & $\begin{array}{l}\text { 10-20 kHz } \\
\text { NBN } \\
\text { (60 dB SPL) }\end{array}$ & $\begin{array}{l}\text { 16-20 kHz } \\
\text { NBN } \\
\text { (60 dB SPL) }\end{array}$ & $\begin{array}{l}\text { 15-17 kHz } \\
\text { NBN } \\
\text { (60 dB SPL) }\end{array}$ \\
\hline \multirow[t]{3}{*}{ Green 1} & Baseline & $2.1 \mathrm{~ms}$ & $2.05 \mathrm{~ms}$ & $4.4 \mathrm{~ms}$ & $3.4 \mathrm{~ms}$ \\
\hline & Saline & $1.8 \mathrm{~ms}$ & $2.5 \mathrm{~ms}$ & $4.3 \mathrm{~ms}$ & NA \\
\hline & Salicylate & $2.0 \mathrm{~ms}$ & $2.9 \mathrm{~ms}$ & $3.7 \mathrm{~ms}$ & $3.4 \mathrm{~ms}$ \\
\hline \multirow[t]{3}{*}{ Green 3} & Baseline & $1.8 \mathrm{~ms}$ & $2.5 \mathrm{~ms}$ & $3.95 \mathrm{~ms}$ & $3.5 \mathrm{~ms}$ \\
\hline & Saline & $1.9 \mathrm{~ms}$ & $2.7 \mathrm{~ms}$ & $4.5 \mathrm{~ms}$ & $3.9 \mathrm{~ms}$ \\
\hline & Salicylate & NA & $2.6 \mathrm{~ms}$ & $3.7 \mathrm{~ms}$ & $3.9 \mathrm{~ms}$ \\
\hline \multirow[t]{3}{*}{ Purple 2} & Baseline & $1.5 \mathrm{~ms}$ & $3.05 \mathrm{~ms}$ & $3.5 \mathrm{~ms}$ & $3.55 \mathrm{~ms}$ \\
\hline & Saline & $1.7 \mathrm{~ms}$ & $2.1 \mathrm{~ms}$ & $4.6 \mathrm{~ms}$ & $3.8 \mathrm{~ms}$ \\
\hline & Salicylate & $1.6 \mathrm{~ms}$ & $5.9 \mathrm{~ms}$ & $6.5 \mathrm{~ms}$ & $7.0 \mathrm{~ms}$ \\
\hline \multirow[t]{3}{*}{ Purple 3} & Baseline & $1.75 \mathrm{~ms}$ & $4.1 \mathrm{~ms}$ & $4.6 \mathrm{~ms}$ & $4.8 \mathrm{~ms}$ \\
\hline & Saline & $1.93 \mathrm{~ms}$ & $3.3 \mathrm{~ms}$ & $4.7 \mathrm{~ms}$ & $5.1 \mathrm{~ms}$ \\
\hline & Salicylate & $1.74 \mathrm{~ms}$ & $3.5 \mathrm{~ms}$ & $4.2 \mathrm{~ms}$ & $5.1 \mathrm{~ms}$ \\
\hline \multirow[t]{3}{*}{ Mean } & Baseline & $1.72 \mathrm{~ms}$ & $2.93 \mathrm{~ms}$ & $4.11 \mathrm{~ms}$ & $3.81 \mathrm{~ms}$ \\
\hline & Saline & $1.93 \mathrm{~ms}$ & $2.65 \mathrm{~ms}$ & $4.53 \mathrm{~ms}$ & $4.27 \mathrm{~ms}$ \\
\hline & Salicylate & $1.74 \mathrm{~ms}$ & $3.73 \mathrm{~ms}$ & $4.53 \mathrm{~ms}$ & $4.85 \mathrm{~ms}$ \\
\hline
\end{tabular}

NA, data not available.

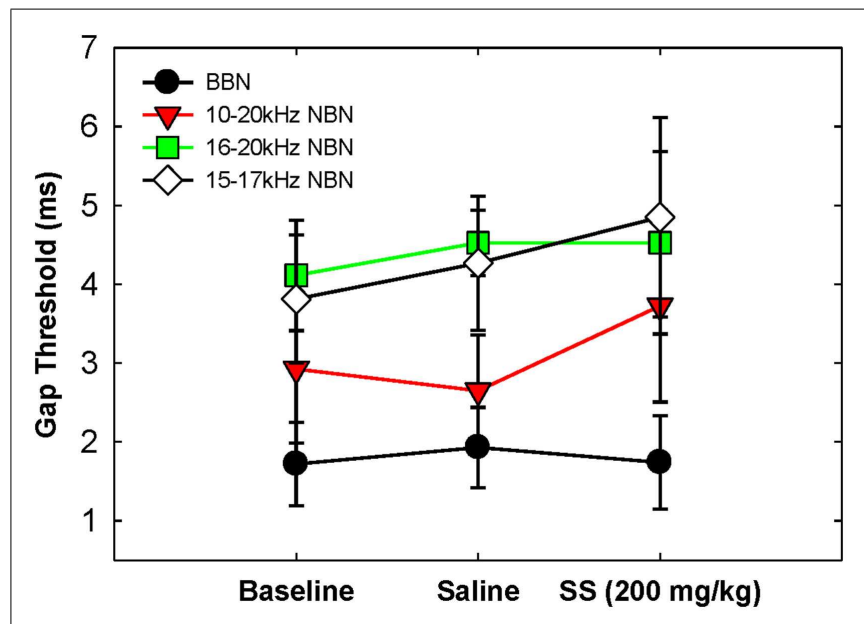

FIGURE 2 | Mean (SEM) gap thresholds for BBN and three NBNs obtained for baseline, saline, and salicylate $(S S, 200 \mathrm{mg} / \mathrm{kg}$ ) conditions.

thresholds could be obtained and one rat had a broken tooth during threshold testing so complete thresholds are shown for three rats). Since one rat, Purple 2, could not perform in the NBN threshold conditions due to a tooth problem, mean performance for the other three rats is plotted in Figure $\mathbf{4}$ and statistics were only carried out using the three rats that could complete all threshold conditions. However, BBN thresholds for rat Purple 2 were included in Table 3 for comparison.

Mean thresholds were the lowest for BBN and the $10-20 \mathrm{kHz}$ NBN and 7-9 dB higher for the $10-20$ and $15-17 \mathrm{kHz}$ NBN. Noise thresholds for BBN, 10-20 kHz NBN, 16-20 kHz NBN, and 15-17
NBN during the salicylate condition increased $\sim 18,19,16$, and $20 \mathrm{~dB}$, respectively, compared to the saline control condition. A two-way repeated measures ANOVA with three conditions (baseline, saline, and salicylate) and four noise bandwidths (BBN, $10-20,16-20$, and $15-17 \mathrm{kHz}$ ) as factors revealed significant main effects of condition $[F(2,35)=322.8, p<0.001]$ and noise bandwidth $[F(3,35)=26.2, p<0.001]$, but there was no significant interaction between condition and bandwidth $[F(6,35)=0.80$, $p>0.05]$. Holm-Sidak post hoc tests found significant differences between the salicylate and saline conditions $(p<0.05)$, and the salicylate and baseline conditions $(p<0.05)$ for all four noises, with the salicylate condition having significantly higher thresholds than the baseline and saline conditions. No significant differences were found between the baseline and saline conditions for any of the noises $(p>0.05)$. The post hoc analyses also revealed significant differences between BBN and the $16-20$ and $15-17 \mathrm{kHz}$ NBNs $(p<0.05)$, but not the $10-20 \mathrm{kHz}$ NBN $(p>0.05)$. Overall, the $16-20$ and $15-17 \mathrm{kHz}$ NBNs consistently produced higher thresholds than the BBN and $10-20 \mathrm{kHz}$ NBN.

\section{DISCUSSION \\ NORMAL GAP DETECTION THRESHOLDS IN RATS}

Most gap detection studies employ BBN stimuli to minimize problems associated with spectral splatter and off-frequency listening $(40,41)$. Our baseline BBN gap detection thresholds in SpragueDawley rats were in the $2-3 \mathrm{~ms}$ range from 30 to $60 \mathrm{~dB}$ SPL ( 28-58 dB SL). However, at $20 \mathrm{~dB}$ SPL ( $18 \mathrm{~dB}$ SL) mean gap thresholds increased to $4.3 \mathrm{~ms}$. Our BBN gap thresholds are in good agreement to those previously reported in rats $(42,43)$, mice $(37,44)$, chinchillas (45), gerbils (35), and humans $(13,40,46)$, and show a clear increase as intensity falls below $30 \mathrm{~dB}$ SPL.

Our NBN gap thresholds measured at $60 \mathrm{~dB}$ SPL were larger than those obtained in BBN (Figure 2; Table 2). The gap thresholds for the two narrowest NBNs (16-20 and $15-17 \mathrm{kHz})$ were $\sim 1$ ms longer than the $10-20 \mathrm{kHz}$ NBN gap threshold, which in turn was roughly $1 \mathrm{~ms}$ longer than the BBN. These results indicate that gap thresholds improve (decrease) as stimulus bandwidth increases. Few animal studies have examined the role of stimulus bandwidth on gap detection performance $(37,47)$ and, to date, no studies have examined the role of frequency and bandwidth on gap detection in rats. However, our results are consistent with human studies that show an improvement in gap thresholds with increasing stimulus bandwidth (48-53).

\section{EFFECTS OF SALICYLATE ON GAP DETECTION THRESHOLDS}

The main goal of the current project was to determine if a dose of salicylate sufficient to induce hearing loss and tinnitus would significantly impair gap detection performance in rats. However, since previous research in normal-hearing humans (40) and animals $(35,37,45)$ has found that gap detection thresholds increase significantly with decreasing stimulus intensity, hearing loss is a primary confounding variable when assessing gap detection thresholds in hearing-impaired listeners. In other words, for all species tested, gap detection thresholds increase with decreasing sound level, regardless of tinnitus or any other temporal processing deficit $(35,40)$. As a result, the hearing loss induced by salicylate needs to be considered when evaluating our gap detection results. 

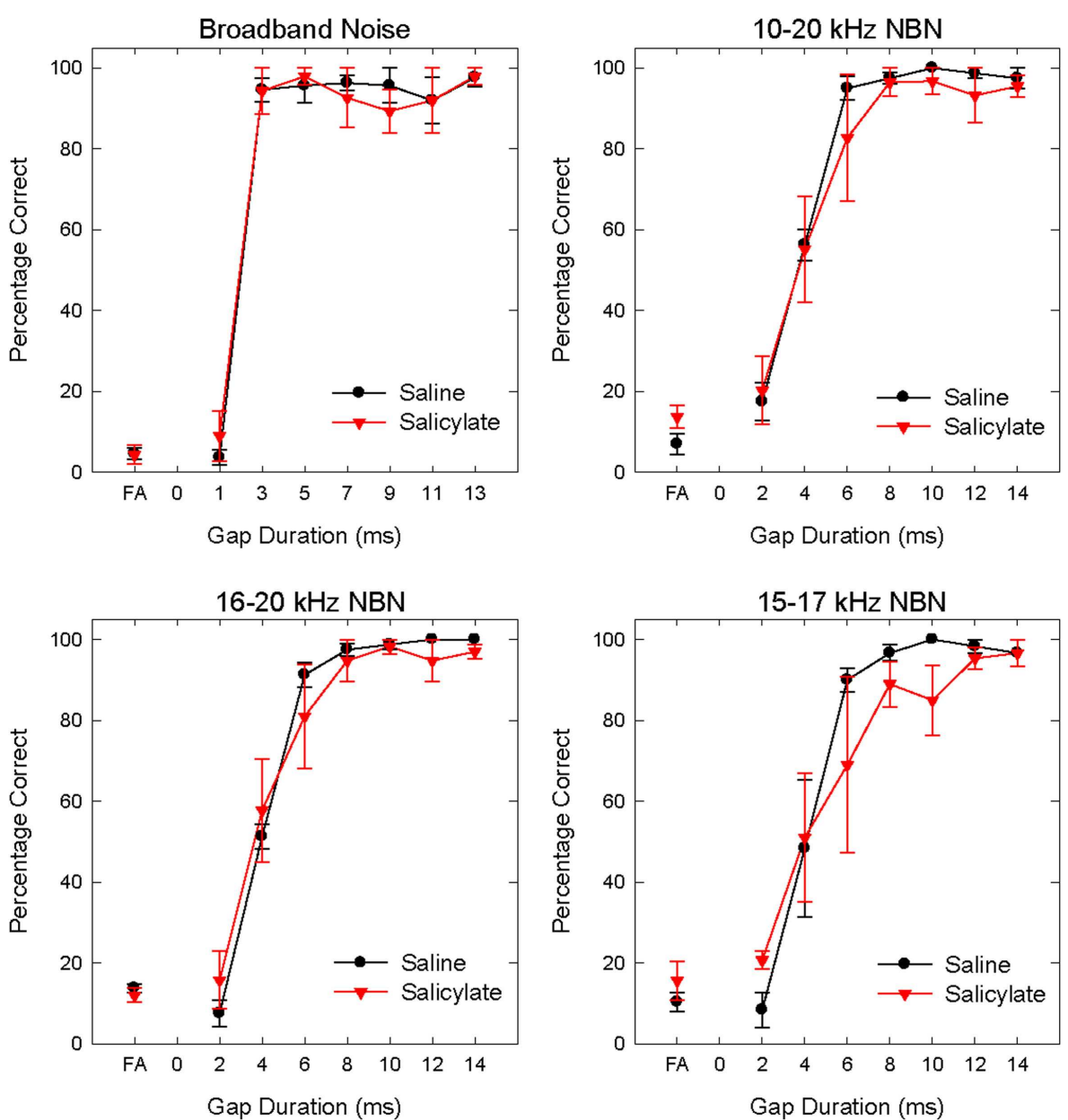

FIGURE 3 | Mean (SEM) psychometric functions in the BBN (60 dB SPL) and NBN (60 dB SPL) gap detection experiments for saline and salicylate (SS, $200 \mathbf{~ m g} / \mathbf{k g}$ ) conditions. False alarm (FA) rates are also plotted.

Because the $200 \mathrm{mg} / \mathrm{kg}$ dose of salicylate increased the BBN threshold from 2 to $19 \mathrm{~dB}$ SPL (Table 3), it was not technically feasible to measure gap thresholds with the $20 \mathrm{~dB}$ SPL BBN due to the fact that the signal was essentially undetectable at this intensity. However, gap thresholds increased to $10 \mathrm{~ms}$ at $30 \mathrm{~dB} \mathrm{SPL}$ (Figure 1); though this increase is most likely due to the fact that the $\mathrm{BBN}$ was now only $10 \mathrm{~dB}$ above threshold versus $\sim 28 \mathrm{~dB}$ above threshold before salicylate treatment (Table 3 ). These results are in line with previous research in animals $(35,37,45)$ and humans $(13$, 40) showing increased gap detection thresholds with decreasing stimulus intensity (Figure 1B).

Gap detection thresholds at 40 and $60 \mathrm{~dB}$ SPL were largely unaffected by salicylate treatment. Likewise, NBN gap detection thresholds measured at $60 \mathrm{~dB}$ SPL were largely unaffected by salicylate treatment; mean gap thresholds increased by $<1.08 \mathrm{~ms}$ post-salicylate when compared to saline values (Figure 2), and salicylate thresholds only appeared to increase in one rat, Purple 2 (Table 2). However, since NBN threshold measurements could not be taken from this rat due to illness, it is possible that this rat had more hearing loss as a result of salicylate treatment than the other rats. This rat's (Purple 2) BBN threshold following salicylate administration was the highest of all four rats tested and was at least 3.6 dB SPL higher than the next highest threshold (Table 3). Taken together, our results mirror gap detection data in humans indicating that salicylate had little or no effect on the detection of silent gaps embedded in BBN or NBN as long as the signals remained audible and well above threshold (13).

Even under the most difficult listening conditions postsalicylate ( $30 \mathrm{~dB}$ SPL BBN), gap thresholds never exceeded $18 \mathrm{~ms}$ in any of the animals tested (Table 1 ). The changes in gap detection we observed in rats treated with $200 \mathrm{mg} / \mathrm{kg}$ salicylate are similar to those observed in humans treated with a high doses of aspirin, whose active ingredient is salicylate (13). The dose of aspirin employed in the McFadden et al. (13) study-induced hearing losses ranging from 4 to $18 \mathrm{~dB}$ in humans. Gap detection thresholds, assessed with low- and high-frequency octave-band noise, were unaffected by the aspirin-induced hearing loss at moderate and high intensities, but increased by $\sim 15 \mathrm{~ms}$ at low intensities. Therefore, as in the McFadden et al. (13) study, the increase in gap thresholds at low SPLs in our experiment is most likely the result 
Table 3 | Individual broadband noise (BBN) and narrowband noise (NBN) thresholds

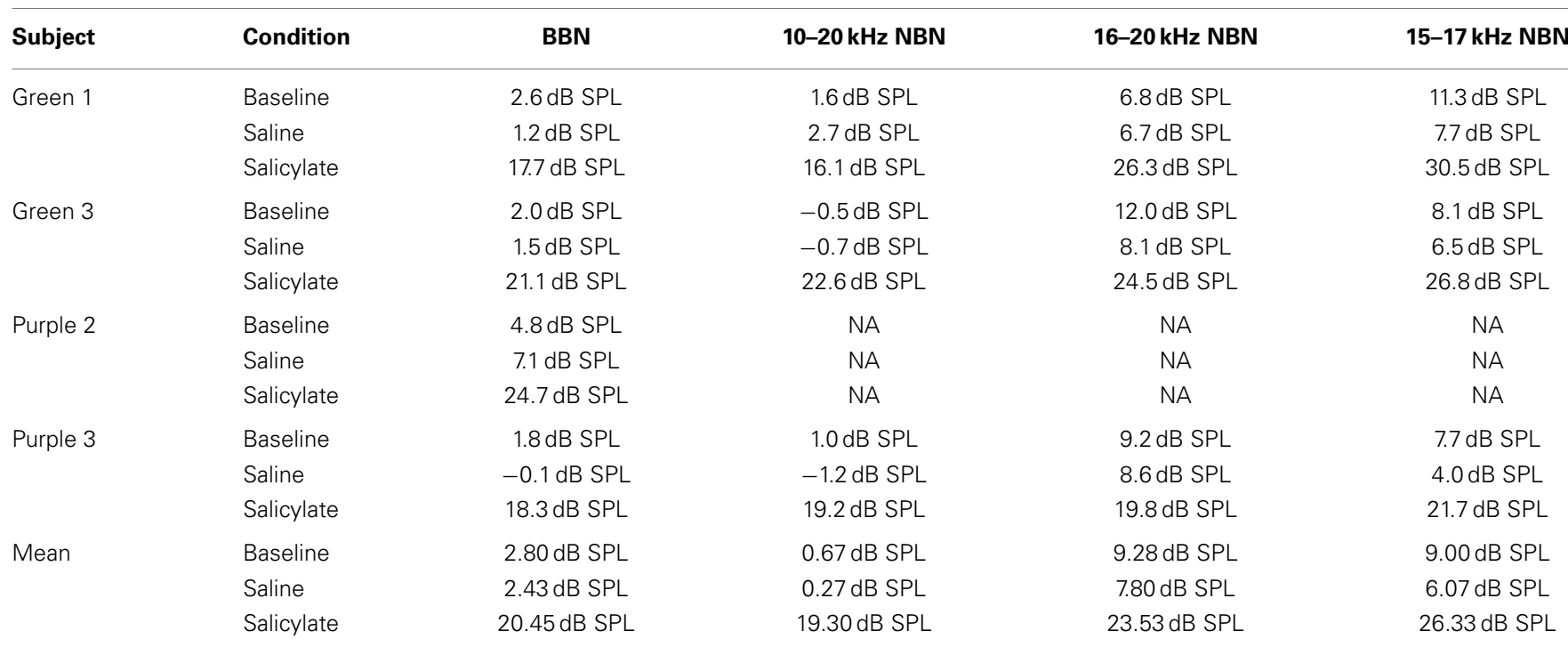

According to this table, a $20 \mathrm{~dB} S P L$ BBN following an injection of salicylate would only be 2.3 and $1.7 \mathrm{~dB}$ above threshold for green 1 and purple 3 , respectively; the $B B N$ would be below threshold for Purple 2 and Green 3

NA, data not available.

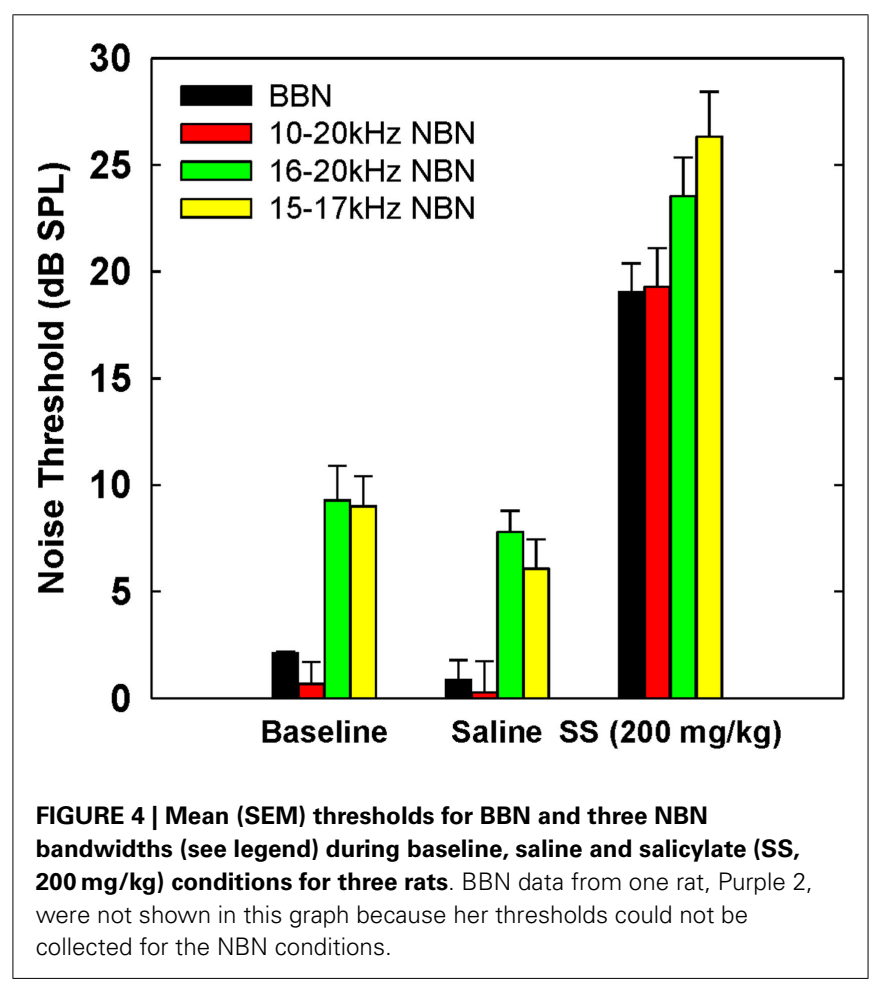

of the salicylate-induced hearing loss rather than an impairment in temporal resolution caused by tinnitus "filling in" the conscious perception of the silent gap.

\section{TINNITUS GAP-FILLING HYPOTHESIS}

In addition to providing important animal psychoacoustic data, our results also have implications for tinnitus research. One of the most widely used animal behavioral models of tinnitus, Gap-PPI, operates on the hypothesis that tinnitus interferes with processing silent gaps in noise $(19,21-23,29,31)$. Most Gap-PPI paradigms employ a $50 \mathrm{~ms}$ silent gap embedded in an ongoing $60 \mathrm{~dB} \mathrm{SPL}$ background noise to suppress the acoustic startle reflex response. Gap stimuli embedded in BBN or NBN strongly inhibit the startle response; but, if an animal is exposed to intense noise or given a high dose of salicylate, the silent gap no longer suppresses the startle response. This lack of prepulse inhibition has been hypothesized to occur because the phantom sound of tinnitus "fills in" the $50 \mathrm{~ms}$ silent intervals in the noise thereby preventing the silent gap from suppressing the subsequent acoustic startle reflex $(19-21,24,25,31)$.

However, this "tinnitus gap-filling" hypothesis has been evaluated in only three human studies to date. Two of these human studies used psychoacoustic procedures to determine whether tinnitus interferes with the conscious perception of silent gaps in noise. Campolo et al. (30) found that when tinnitus patients with pre-existing hearing loss were asked if they could detect $50 \mathrm{~ms}$ silent gaps embedded in $15 \mathrm{~dB}$ SL NBN that was centered above, below, or at their tinnitus frequency, tinnitus patients had no difficulty detecting the $50 \mathrm{~ms}$ gaps and performed as well as normalhearing subjects (30). More recently, Boyen et al. (54) found that human tinnitus patients had similar gap detection thresholds compared to a matched non-tinnitus control group even when the test frequency matched the patient's tinnitus frequency (54).

The third recent human study used an eye-blink Gap-PPI paradigm to test gap detection in tinnitus patients (55). Fournier and Hébert (55) found that patients with high-frequency hearing loss and high-pitched tinnitus had less Gap-PPI than normal controls at high frequencies, but they also had less Gap-PPI at low frequencies where there was no tinnitus. If the high-pitched tinnitus was filling in the silent gap, the authors reasoned that 
the tinnitus patients should have impaired Gap-PPI only at the high frequencies and not the low frequencies (55). Furthermore, since the tinnitus group in the Fournier and Hébert (55) study had a high-frequency hearing loss while the control group did not, it is not surprising that their tinnitus subjects would show greater gap detection deficits than the control subjects given that previous research has shown that high-frequency information is important for sensitive gap detection performance. When high frequencies are unavailable to a subject, either through a hearing loss or through filtering of the test stimuli, gap detection thresholds increase $(15,37,40,42,48)$.

Our current psychophysical results provide the first test of the "tinnitus gap-filling" hypothesis in an animal. The results of our gap detection experiment mirror the results found in the human psychophysical gap detection tests $(13,30,54)$, and suggest that tinnitus does not "fill-in" the silent gap in tasks requiring conscious perception.

\section{THE CONFOUNDING EFFECTS OF SALICYLATE AND NOISE EXPOSURE}

One of the difficulties in developing an animal behavioral model of tinnitus is controlling for the confounding effects of the tinnitus inducer, i.e., salicylate or noise exposure $(18,56)$. In addition to tinnitus, salicylate is also known to induce hearing loss in humans and animals $(1,13)$, temporal resolution and integration deficits in humans (13), and hyperacusis in animals $(22,57)$. Therefore, any animal behavioral paradigm must account for these confounding variables when assessing animals for tinnitus.

Researchers using Gap-PPI, including our lab, have attempted to account for salicylate-induced hearing loss and gap detection deficits by using background noises of at least $60 \mathrm{~dB}$ SPL and $50 \mathrm{~ms}$ silent gaps $(19-21,24)$. Using these, and similar, stimulus parameters, researchers have consistently found Gap-PPI deficits, i.e., reduced inhibition, in animals following salicylate exposure and have attributed these deficits to the presence of tinnitus $(19,20)$. However, the results of the current experiment, along with recent human psychoacoustic and startle reflex data, call into question what the Gap-PPI paradigm is modeling (32). If hearing loss and gap detection deficits are not producing these changes in Gap-PPI because the stimuli are presented at high sound levels ( $\sim 60 \mathrm{~dB}$ SPL), with long-duration gaps $(\sim 50 \mathrm{~ms})$, and if tinnitus is not filling in the silent gaps, as suggested by the current results and recent human data $(30,54,55)$, then it is not yet clear what is producing Gap-PPI deficits following salicylate and noise exposure.

One explanation for the changes in Gap-PPI following salicylate or noise exposure could be related to hyperacusis. Briefly, hyperacusis is defined as abnormal sound level tolerance where moderate-level sounds are perceived as uncomfortably loud (58, 59). Both salicylate and noise exposure have recently been implicated in the manifestation of hyperacusis in animals. Salicylate has been shown to amplify acoustic startle responses (ASRs) $(8,20)$ and alter loudness growth functions to moderate- and high-level sounds (57) in rats. In addition, noise exposures that result in either permanent threshold shifts (22) or only temporary threshold shifts (60) have been shown to amplify ASRs in animals, which may be indicative of hyperacusis (18). Given these consistent changes to ASRs following salicylate and noise exposure, this could be a confounding variable when measuring Gap-PPI because PPI is not independent from baseline startle reactivity $(61,62)$.

Another explanation for changes in Gap-PPI following salicylate are alterations in temporal processing. Sun et al. (63) found that salicylate facilitates the perception of the onset of the gap, but reduces the perception of the offset of the gap. In other words, salicylate increases Gap-PPI by facilitating the response to the onset of the gaps, while decreasing Gap-PPI when the offset of the gap is the available cue (63). Since salicylate facilitated the ASR, (63) determined that these changes were not due to hearing loss. However, since temporal integration is altered in humans given large doses of aspirin (13), and since salicylate enhances the sound-evoked onset responses of cortical neurons (9), it is possible that changes in temporal integration following salicylate could explain the Sun et al. (63) results, regardless of tinnitus.

Although the Gap-PPI paradigm has many advantages over other animal models of tinnitus, it is not yet clear that tinnitus alone can account for changes in Gap-PPI when both salicylate and noise exposure appear to induce hearing loss, temporal processing deficits, and hyperacusis as well $(18,32)$.

\section{CONCLUDING REMARIKS}

In summary, the gap detection thresholds for rats in the current study were unchanged with salicylate for BBN and NBN presented at high-sound levels, suggesting that salicylate-induced tinnitus was not "filling in" the conscious perception of the silent gaps. Furthermore, given the threshold shifts found in the noise detection experiments, the effects of salicylate on gap detection at low-sound levels are most parsimoniously explained by hearing loss alone and not caused by tinnitus. However, the possibility remains that tinnitus interferes with peripheral, pre-attentive filtering of sensory stimuli involved in sensorimotor gating. As such, the conscious perception of silent gaps in background noise may involve different neural processes than those underlying prepulse inhibition of the acoustic startle reflex; however, hearing loss, temporal processing deficits, and hyperacusis remain confounding variables when using traditional gap detection paradigms to measure tinnitus in animals.

\section{AUTHOR CONTRIBUTIONS}

$\mathrm{KR}, \mathrm{DS}$, and RS conceptualized and designed the experiment. KR, $M U$, and RB collected and analyzed the data. KR and RS interpreted the data and wrote the manuscript. KR, DS, MU, RB, and $\mathrm{RS}$ revised the manuscript and approved the final version.

\section{ACKNOWLEDGMENTS}

This research was supported in part by grants from NIH (R01DC011808) and Office of Naval Research (N000141210731).

\section{REFERENCES}

1. Brennan JF, Brown CA, Jastreboff PJ. Salicylate-induced changes in auditory thresholds of adolescent and adult rats. Dev Psychobiol (1996) 29:69-86. doi:10.1002/(SICI)1098-2302(199601)29:1<69::AID-DEV4>3.3.CO;2-R

2. Cazals Y. Auditory sensori-neural alterations induced by salicylate. Prog Neurobiol (2000) 62:583-631. doi:10.1016/S0301-0082(00)00027-7

3. Chen GD, Stolzberg D, Lobarinas E, Sun W, Ding D, Salvi R. Salicylate-induced cochlear impairments, cortical hyperactivity and re-tuning, and tinnitus. Hear Res (2013) 295:100-13. doi:10.1016/j.heares.2012.11.016 
4. Stolzberg D, Hayes SH, Kashanian N, Radziwon K, Salvi RJ, Allman BL. A novel behavioral assay for the assessment of acute tinnitus in rats optimized for simultaneous recording of oscillatory neural activity. J Neurosci Methods (2013) 219:224-32. doi:10.1016/j.jneumeth.2013.07.021

5. Sheppard A, Hayes SH, Chen G-D, Ralli M, Salvi R. Review of salicylate-induced hearing loss, neurotoxicity, tinnitus and neuropathophysiology. Acta Otorhinolaryngol Ital (2014) 34:79-93.

6. Chen G-D, Kermany MH, D’Elia A, Ralli M, Tanaka C, Bielefeld EC, et al. Too much of a good thing: long-term treatment with salicylate strengthens outer hair cell function but impairs auditory neural activity. Hear Res (2010) 265:63-9. doi:10.1016/j.heares.2010.02.010

7. Stolzberg D, Chen GD, Allman BL, Salvi RJ. Salicylate-induced peripheral auditory changes and tonotopic reorganization of auditory cortex. Neuroscience (2011) 180:157-64. doi:10.1016/j.neuroscience.2011.02.005

8. Sun W, Lu J, Stolzberg D, Gray L, Deng A, Lobarinas E, et al. Salicylate increases the gain of the central auditory system. Neuroscience (2009) 159:325-34. doi:10.1016/j.neuroscience.2008.12.024

9. Stolzberg D, Chrostowski M, Salvi RJ, Allman BL. Intracortical circuits amplify sound-evoked activity in primary auditory cortex following systemic injection of salicylate in the rat. J Neurophysiol (2012) 108:200-14. doi:10.1152/jn.00946. 2011

10. Ochi K, Eggermont JJ. Effects of salicylate on neural activity in cat primary auditory cortex. Hear Res (1996) 95:63-76. doi:10.1016/0378-5955(96)00019-6

11. Johnson NJ, Elberling C. Evoked acoustic emissions from the human ear: I. Equipment and response parameters. Scand Audiol (1982) 11:3-12. doi:10.3109/ 01050398209076194

12. McFadden D, Plattsmier HS. Aspirin can potentiate the temporary hearing loss induced by intense sounds. Hear Res (1983) 9:295-316. doi:10.1016/03785955(83)90033-3

13. McFadden D, Plattsmier HS, Pasanen EG. Aspirin-induced hearing loss as a model of sensorineural hearing loss. Hear Res (1984) 16:251-60. doi:10.1016/ 0378-5955(84)90114-X

14. McFadden D, Wightman FL. Audition: some relations between normal and pathological hearing. Annu Rev Psychol (1983) 34:95-128. doi:10.1146/annurev. ps.34.020183.000523

15. Salvi RJ, Arehole S. Gap detection in chinchillas with temporary high-frequency hearing loss. J Acoust Soc Am (1985) 77:1173-7. doi:10.1121/1.392181

16. Jastreboff PJ, Brennan JF, Coleman JK, Sasaki CT. Phantom auditory sensation in rats: an animal model for tinnitus. Behav Neurosci (1988) 102:811-22. doi:10.1037/0735-7044.102.6.811

17. von der Behrens W. Animal models of subjective tinnitus. Neural Plast (2014) 2014:741452. doi:10.1155/2014/741452

18. Hayes SH, Radziwon KE, Stolzberg DJ, Salvi RJ. Behavioral models of tinnitus and hyperacusis in animals. Front Neurol (2014) 5:179. doi:10.3389/fneur.2014. 00179

19. Yang G, Lobarinas E, Zhang L, Turner J, Stolzberg D, Salvi R, et al. Salicylate induced tinnitus: behavioral measures and neural activity in auditory cortex of awake rats. Hear Res (2007) 226:244-53. doi:10.1016/j.heares.2006.06.013

20. Turner JG, Parrish J. Gap detection methods for assessing salicylate-induced tinnitus and hyperacusis in rats. Am J Audiol (2008) 17:S185-92. doi:10.1044/ 1059-0889(2008/08-0006)

21. Longenecker RJ, Galazyuk AV. Development of tinnitus in CBA/CaJ mice following sound exposure. J Assoc Res Otolaryngol (2011) 12:647-58. doi:10.1007/ s10162-011-0276-1

22. Chen G, Lee C, Sandridge SA, Butler HM, Manzoor NF, Kaltenbach JA. Behavioral evidence for possible simultaneous induction of hyperacusis and tinnitus following intense sound exposure. J Assoc Res Otolaryngol (2013) 14:413-24. doi:10.1007/s10162-013-0375-2

23. Pace E, Zhang J. Noise-induced tinnitus using individualized gap detection analysis and its relationship with hyperacusis, anxiety, and spatial cognition. PLoS One (2013) 8:e75011. doi:10.1371/journal.pone.0075011

24. Berger JI, Coomber B, Wells TT, Wallace MN, Palmer AR. Changes in the response properties of inferior colliculus neurons relating to tinnitus. Front Neurol (2014) 5:203. doi:10.3389/fneur.2014.00203

25. Coomber B, Berger JI, Kowalkowski VL, Shackleton TM, Palmer AR, Wallace MN. Neural changes accompanying tinnitus following unilateral acoustic trauma in the guinea pig. Eur J Neurosci (2014) 40:2427-41. doi:10. 1111/ejn. 12580
26. Ison JR. Temporal acuity in auditory function in the rat: reflex inhibition by brief gaps in noise. J Comp Physiol Psychol (1982) 96:945-54. doi:10.1037/07357036.96.6.945

27. Ison JR, Taylor MK, Bowen GP, Schwarzkopf SB. Facilitation and inhibition of the acoustic startle reflex in the rat after a momentary increase in background noise level. Behav Neurosci (1997) 111:1335-52. doi:10.1037/0735-7044.111.6. 1335

28. Cooper JCJ. Health and nutrition examination survey of 1971-75: Part II. Tinnitus, subjective hearing loss, and well-being. J Am Acad Audiol (1994) 5: 37-43.

29. Turner JG, Brozoski TJ, Bauer CA, Parrish JL, Myers K, Hughes LF, et al. Gap detection deficits in rats with tinnitus: a potential novel screening tool. Behav Neurosci (2006) 120:188-95. doi:10.1037/0735-7044.120.1.188

30. Campolo J, Lobarinas E, Salvi R. Does tinnitus "fill in" the silent gaps? Noise Health (2013) 15:398-405. doi:10.4103/1463-1741.121232

31. Dehmel S, Eisinger D, Shore SE. Gap prepulse inhibition and auditory brainstem-evoked potentials as objective measures for tinnitus in guinea pigs. Front Syst Neurosci (2012) 6:42. doi:10.3389/fnsys.2012.00042

32. Eggermont JJ. Hearing loss, hyperacusis, or tinnitus: what is modeled in animal research? Hear Res (2013) 295:140-9. doi:10.1016/j.heares.2012.01.005

33. Lobarinas E, Sun W, Cushing R, Salvi R. A novel behavioral paradigm for assessing tinnitus using schedule-induced polydipsia avoidance conditioning (SIPAC). Hear Res (2004) 190:109-14. doi:10.1016/S0378-5955(04)00019-X

34. Steckler T. Using signal detection methods for analysis of operant performance in mice. Behav Brain Res (2001) 125:237-48. doi:10.1016/S0166-4328(01) 00305-9

35. Wagner E, Klump GM, Hamann I. Gap detection in Mongolian gerbils (Meriones unguiculatus). Hear Res (2003) 176:11-6. doi:10.1016/S0378-5955(02)00643-3

36. Klink KB, Bendig G, Klump GM. Operant methods for mouse psychoacoustics. Behav Res Methods (2006) 38:1-7. doi:10.3758/BF03192744

37. Radziwon KE, June KM, Stolzberg DJ, Xu-Friedman MA, Salvi RJ, Dent ML. Behaviorally measured audiograms and gap detection thresholds in CBA/CaJ mice. J Comp Physiol A Neuroethol Sens Neural Behav Physiol (2009) 195:961-9. doi:10.1007/s00359-009-0472-1

38. Klump GM, Maier EH. Gap detection in the starling (Sturnus vulgaris). J Comp Physiol A (1989) 164:531-8. doi:10.1016/j.visres.2010.09.020

39. Brennan JF, Jastreboff PJ. Generalization of conditioned suppression during salicylate-induced phantom auditory perception in rats. Acta Neurobiol Exp (1991) 51:15-27.

40. Fitzgibbons PJ. Temporal gap resolution in narrow-band noises with center frequencies from 6000-14000 Hz. J Acoust Soc Am (1984) 75:566-9. doi:10.1121/1. 390529

41. Shailer MJ, Moore BCJ. Detection of temporal gaps in bandlimited noise: effects of variations in bandwidth and signal-to-masker ratio. J Acoust Soc Am (1985) 77:635-9. doi:10.1121/1.391881

42. Syka J, Rybalko N, Mazelová J, Druga R. Gap detection threshold in the rat before and after auditory cortex ablation. Hear Res (2002) 172:151-9. doi:10.1016/S0378-5955(02)00578-6

43. Rybalko N, Syka J. Effect of noise exposure on gap detection in rats. Hear Res (2005) 200:63-72. doi:10.1016/j.heares.2004.08.014

44. Walton JP, Frisina RD, Ison JR, O'Neill WE. Neural correlates of behavioral gap detection in the inferior colliculus of the young CBA mouse. J Comp Physiol A (1997) 181:161-76. doi:10.1007/s003590050103

45. Giraudi D, Salvi R, Henderson D, Hamernik R. Gap detection by the chinchilla. J Acoust Soc Am (1980) 68:802-6. doi:10.1121/1.384818

46. Plomp R. Rate of decay of auditory sensation. JAcoust Soc Am (1964) 36:277-82. doi:10.1121/1.1918946

47. Ison JR, Allen PD, Rivoli PJ, Moore JT. The behavioral response of mice to gaps in noise depends on its spectral components and its bandwidth. J Acoust Soc Am (2005) 117:3944-51. doi:10.1121/1.1904387

48. Buus S, Florentine M. Gap detection in normal and impaired listeners: the effect of level and frequency. In: Michelsen A, editor. Time Resolution in Auditory Systems. New York, NY: Springer-Verlag (1985). p. 159-79.

49. Formby C, Muir K. Modulation and gap detection for broadband and filtered noise signals. J Acoust Soc Am (1988) 84:545-50. doi:10.1121/1.396831

50. Grose JH, Eddins DA, Hall JWI. Gap detection as a function of stimulus bandwidth with fixed high-frequency cutoff in normal-hearing and hearing-impaired listeners. J Acoust Soc Am (1989) 86:1747-55. doi:10.1121/1.398606 
51. Grose JH. Gap detection in multiple narrow bands of noise as a function of spectral configuration. J Acoust Soc Am (1991) 90:3061-8. doi:10.1121/1.401780

52. Eddins DA, Hall JWI, Grose JH. The detection of temporal gaps as a function of frequency region and absolute noise bandwidth. J Acoust Soc Am (1992) 91:1069-77. doi:10.1121/1.402633

53. Snell KB, Ison JR, Frisina DR. The effects of signal frequency and absolute bandwidth on gap detection in noise. J Acoust Soc Am (1994) 96:1458-64. doi:10.1121/1.410288

54. Boyen K, Baskent D, van Dijk P. Gap detection thresholds in tinnitus subjects: does tinnitus fill in the silent gaps? 8th International TRI Tinnitus Conference. Auckland (2014).

55. Fournier P, Hébert S. Gap detection deficits in humans with tinnitus as assessed with the acoustic startle paradigm: does tinnitus fill in the gap? Hear Res (2013) 295:16-23. doi:10.1016/j.heares.2012.05.011

56. Heffner HE, Heffner RS. Behavioral tests for tinnitus in animals. In: Eggermont JJ, Zeng F-G, Popper AN, Fay RR, editors. Tinnitus. New York, NY: Springer Science+Business Media (2012). p. 21-58.

57. Chen G-D, Radziwon KE, Kashanian N, Manohar S, Salvi R. Salicylate-induced auditory perceptual disorders and plastic changes in nonclassical auditory centers in rats. Neural Plast (2014) 2014:658741. doi:10.1155/2014/658741

58. Blaesing L, Kroener-Herwig B. Self-reported and behavioral sound level avoidance in tinnitus and hyperacusis subjects, and association with anxiety ratings. Int J Audiol (2012) 51:611-7. doi:10.3109/14992027.2012.664290

59. Tyler RS, Pienkowski M, Roncancio ER, Jun HJ, Brozoski T, Dauman N, et al. A review of hyperacusis and future directions: part I. Definitions and manifestations. Am J Audiol (2014) 23(4):402-19. doi:10.1044/2014_AJA-14-0010

60. Hickox AE, Liberman MC. Is noise-induced cochlear neuropathy key to the generation of hyperacusis or tinnitus? J Neurophysiol (2014) 111:552-64. doi:10.1152/jn.00184.2013
61. Csomor PA, Yee BK, Vollenweider FX, Feldon J, Nicolet T, Quednow BB. On the influence of baseline startle reactivity on the indexation of prepulse inhibition. Behav Neurosci (2008) 122:885-900. doi:10.1037/0735-7044. 122.4.885

62. Lobarinas E, Hayes SH, Allman BL. The gap-startle paradigm for tinnitus screening in animal models: limitations and optimization. Hear Res (2013) 295:150-60. doi:10.1016/j.heares.2012.06.001

63. Sun W, Doolittle L, Flowers E, Zhang C, Wang Q. High doses of salicylate causes prepulse facilitation of onset-gap induced acoustic startle response. Behav Brain Res (2014) 258:187-92. doi:10.1016/j.bbr.2013.10.024

Conflict of Interest Statement: The authors declare that the research was conducted in the absence of any commercial or financial relationships that could be construed as a potential conflict of interest.

Received: 23 October 2014; accepted: 07 February 2015; published online: 20 February 2015.

Citation: Radziwon KE, Stolzberg DJ, Urban ME, Bowler RA and Salvi RJ (2015) Salicylate-induced hearing loss and gap detection deficits in rats. Front. Neurol. 6:31. doi: 10.3389/fneur.2015.00031

This article was submitted to Neuro-otology, a section of the journal Frontiers in Neurology.

Copyright (C) 2015 Radziwon, Stolzberg, Urban, Bowler and Salvi. This is an openaccess article distributed under the terms of the Creative Commons Attribution License (CC BY). The use, distribution or reproduction in other forums is permitted, provided the original author(s) or licensor are credited and that the original publication in this journal is cited, in accordance with accepted academic practice. No use, distribution or reproduction is permitted which does not comply with these terms. 